\title{
Niños que lo han visto todo: Cuerpo, destrucción y vejez en la poesía de Gonzalo Millán*
}

\author{
Children who have seen everything: Body, destruction and aging in the poetry of \\ Gonzalo Millán
}

Claudio Guerrero

Pontificia Universidad Católica de Valparaíso, Valparaíso, Chile. Correo electrónico: cmguerrev@gmail.com

Este trabajo realiza una articulación crítica de la representación de la infancia en la poesía de Gonzalo Millán. Presente a lo largo de toda su obra, dicha representación es tensionada a partir de un niño metamorfoseado en animal como parte de un plan que instaura una experiencia desacralizada de la niñez, que posteriormente se vivencia a lo largo de las etapas de la vida como crisis en el marco de la vida moderna, pero también como posibilidad creativa y como vínculo desde la vejez, en cuanto puesta en escena memorialista de un sujeto que se mira al espejo y busca pintarse a sí mismo ante la proximidad de la muerte.

Palabras clave: infancia, poesía chilena, cuerpo, destrucción, vejez

This paper realizes a critical joint of the representation of childhood in Gonzalo Millán's poetry. Such representation, present along all his work, is tensed from a child transformed in animal as part of a plan who restores a desacralize experience of childhood that later experience along the stages of the life like crisis in the frame of the modern life, but also as creative possibility and as link from the oldness in all that memorious put in scene of a subject that looks at the mirror and seeks draw his self before the proximity of the death.

Key words: childhood, Chilean poetry, body, destruction, oldness

Ese rinconcito de existencia confusa que es la infancia.

Michel Foucault.

Este trabajo forma parte del proyecto Fondecyt $\mathrm{N}^{\circ} 11121276$ : "Representaciones de infancia en la poesía chilena de segunda mitad del siglo XX". 


\section{INTRODUCCIÓN}

La poesía de Gonzalo Millán (1947-2008), perteneciente a la experimentadora generación de poetas que se posicionó en el campo cultural chileno de los años sesenta y comienzos del setenta ${ }^{1}$, es una poesía poblada de niños. De niños "que ya lo han visto todo" (Zaldívar 1998: E16). Niños a quienes el polvo de los siglos encanece en unos segundos, como señala el poema "Bautismo de polvo" en Relación personal ([1968] 2006). Postulamos como hipótesis central de nuestro trabajo que a lo largo de la obra millaniana estos niños que tempranamente han sido bautizados por el polvo y cumplido su edad, van mutando de manera compleja de acuerdo a diferentes momentos e intencionalidades poéticas dentro de la producción del autor nacido en Concepción, pero siempre bajo el decurso simbólico de una prematura vejez.

Identificamos en la poesía de Millán al menos cuatro formas de concebir poéticamente la infancia, las cuales nos parecen relevantes de problematizar aquí: a) la idea de un niño cuyo cuerpo metamorfoseado en animal se exhibe tensionado por la ironía de los primeros poemas de su libro inaugural Relación personal, como parte de un plan que instaura una experiencia desacralizada de la infancia; b) la de un adulto inserto en la sociedad contemporánea que vive el imperativo de la existencia moderna de conformar una familia y tener hijos dando a entender, de paso, las huellas que la vida adulta y la modernidad dejan en los niños, cuestionamientos que aparecen esencialmente en Vida (1984); c) la de un sujeto escribiente del poema largo La ciudad ([1979] 1997 -y posteriores reediciones con cambios sustantivos-), que se autodefine como una anciana que utiliza una estructura especular para dar a luz un niño anciano: el poema, y; d) la de un sujeto en la etapa final de su vida, próximo a la muerte, que vincula infancia y vejez como los extremos de una existencia desgarrada, fragmentada, que se mira al espejo y busca pintarse, situación que se expresa en su postrera producción Autorretrato de memoria (2005) y en su diario de muerte Veneno de escorpión azul (2007).

\section{UN CUERPO-BICHO}

Relación personal $^{2}$ es la relatoría no personal ${ }^{3}$ de una trayectoria vital de un sujeto que irónica y desacralizadamente alude a la infancia, la adolescencia y la iniciación

Unos más neovanguardistas que otros (postparrianos, pero aún tributarios de esa matriz), el campo poético de los sesenta estaba centrado especialmente en grupos literarios extracapitalinos: Tebaida (Arica), Arúspice (Concepción) y Trilce (Valdivia), y en poetas dispersos, independientes, sin arrimo alguno a grupo literario, todos los cuales coexistían sin entrar en grandes conflictos entre sí ni con la generación anterior, pero diferenciándose de ella por un mayor formalismo estilístico (Campos 1987: 17). Se trata de una generación que amplía los códigos expresivos de la lírica, tomando como antecedentes la primera vanguardia, el pop art, la poesía concreta y las técnicas del cine, y fundamentalmente explorando la relación entre palabra e imagen. Se trata de una poesía que desconfía del carácter mesiánico del lenguaje y su nerudiana retórica inflamada, convirtiéndose en un "contralenguaje" (Galindo 2007: 109).

2 Existen diferentes versiones de este libro, todas con variantes significativas: la primera, de 1968; la de 1982, que es la primera parte de Vida; la de 1997, de la antología Trece lunas; y, la de 2006, que agrega tres poemas de juventud. Hemos decidido trabajar con la última versión. Éste es un problema de la obra entera de Millán, que plantea la idea de un texto no definitivo ni monumental, sino que en transición temporal, capaz de rehacerse, corregirse y reescribirse, incluso permitiendo el traslado, agregado y quite de poemas, otorgándole a su poesía una "indudable apertura y flexibilidad funcional" (Foxley 1991: 55).

3 Inaugura el libro un epígrafe -no contemplado en la primera edición de 1968 y sí en la segunda de 1984- del poeta norteamericano de la primera mitad del siglo XX, Wallace Stevens, que dice: "La poesía no es personal", y que marca la conciencia poética del autor por construir un edificio basado en la despersonalización, alejado del yo 
sexual. Es un libro que busca la descentralización del sujeto: "Cómo aniquilar las tecnologías del yo, volverlas pedacitos de lenguaje, para luego saldar con esos trozos la diáspora lírica de las edades del hombre" (Arroyo 2012: 9). Mediante el uso de giros coloquiales, imágenes feístas ${ }^{4}$, disonancias entre título y contenido que generan amplitud semántica y recurrencias que remiten a lo táctil y sonoro, se nos presenta en la primera parte de este poemario a un sujeto infantil que luego deviene en adolescente y que experimenta con el mundo objetual y establece particulares sensibilidades, en especial aquellas que remiten al mundo animal.

En efecto, hay en este libro en específico y a lo largo de toda su poesía una constante metaforización de la experiencia a través de alusiones a seres vivos como el reptil, la culebra, el caracol, la langosta, la sanguijuela y otros, recurriendo especialmente a la experiencia táctil que deriva "en furtivos gestos transgresores" (Foxley 1991: 58), violentos e inquietantes. Por una parte, el sujeto se autorrepresenta como un niño que experimenta con ellos como en "Historieta del blanco niño gordo y la langosta", a quien se le escapa una sonrisa de la boca "al ver volar desde mis manos / desnudas hacia el polvo / las patas y las alas / arrancadas por mis uñas” (Millán [1968] 2006: 21) de un insecto. Por otra parte, se metamorfosea primordialmente en animales de tierra como "En blancas carrozas viajamos", poema que nos muestra a un sujeto que, como el caracol, se arrastra por la tierra, oculto entre "hollejos de frutas / y humaredas de hojas y papeles" (p. 22), dejando una estela húmeda de babosa a su paso, sobre los muslos de una mujer, al mismo tiempo que se endurece en sus manos sucias "la celeste cornamenta de mis venas" (p. 22). Ambas instancias signan una infancia que prontamente se acaba, que no da cabida a ningún tipo de inocencia: cuando se pierde el asombro y la sonrisa para dar paso a la extrañeza, en el primer poema, o, cuando se introduce ya una conciencia de la sexualidad, indicando rápidamente que el niño que aquí se presenta viajando -imaginariamente infantil- en blancas carrozas, no es tal.

Este sujeto disociado, que se hace presente en la imagen de un niño que no parece niño sino que adolescente animalizado en la langosta trituradora o el caracol baboso, se explota irónicamente en la poesía de Millán cuando en un poema como "Toco rondas infantiles con una mueca en los labios", el hablante profundiza en la desacralización de la tradicional imagen del niño ingenuo y cándido, por un lado, y la tradición de las rondas infantiles, por otro lado. Esto se da al presentar un sujeto que, "con grandes manos" toca un piano de juguete ${ }^{6}$, con una mueca en los labios,

autobiográfico. En cuanto al título, como apunta Morales (2009: 48), la idea de una Relación opera desde una doble discursividad: como vínculo entre una cosa y otra, pero también como relato, como narración, en tanto referencia a la modalidad textual de las Cartas de Relación del periodo colonial.

4 Algunas de las características recursivas que tempranamente se expresan en la poesía de Millán y que se mantienen a lo largo de su poesía son, precisamente, la recurrencia a un feísmo estético, junto con "la destrucción casi patológica de los espacios de amparo de la cotidianeidad y el distanciamiento expresivo, o la búsqueda de una interioridad neutral para referirse a los elementos del mundo" (Galindo 2004: 71).

5 Es recurrente en este poemario, también, esta forma de titular. En el caso específico de la historieta, remite al cómic, al texto ilustrado en viñetas para niños y jóvenes. En su envoltorio, gran parte de estos poemas tienen esa visibilidad, la posibilidad de constituirse como dibujos de una revista. También resulta curioso de este poema que el "blanco niño gordo" y "la langosta" del título no aparezcan explicitados en el texto, lo que reafirma la idea del establecimiento distante de relaciones entre títulos y contenidos de los poemas, hecho que permite el reclamo de autonomía para uno y otro. Además, el exceso descriptivo del título introduce "un matiz grotesco" (Foxley 1991: 61) que pareciera distanciar aún más las implicancias textuales de dicha relación.

6 Grandes manos que, a su vez, plantean una disonancia entre cuerpo y objeto, una desarmonía y una desproporción como símbolo del desajuste del sujeto y su extraña configuración corpórea. 
mientras se describe una escena cuyo eje protagónico es un niño. Mueca, diríamos, de sorna al presentarnos a este otro niño que describe como un animal baboso de tierra, a quien se le pegan los pétalos de las flores en los labios, las cuales comienza a morder. Se trata, como dijimos, de un niño-bicho que no pareciera concordar con su edad y con su cuerpo, un niño, además, puesto al lado, sinecdóticamente, de un muñeco podrido bajo tierra, ciruelas que pierden su ácido sabor y "carcomidas lanzas de madera de una reja" (p. 23), es decir, con una negatividad semántica (podridoperder-carcomido) que nos lleva a la idea de un niño que ha mutado, que ha dejado de ser niño. Bajo este panorama, cualquier alusión que se haga a una ronda infantil no deja de ser un gesto amargo para intensificar justamente su contrario semántico, que no es otra cosa que la función de la ironía; una de las características esenciales de esta poesía que busca hacer visibles los posibles reversos del mundo.

En este contexto de profundo y corrosivo sarcasmo es posible entender la función que cumplen las alusiones a las historietas y sus personajes. Todos héroes animales (el lagarto, la langosta, la mariposa, el caracol, etc.), personajes del tradicional cuento infantil de las fábulas moralizantes, sumados a las alusiones a colores como el rojo, el azul, el verde, etc., y al hecho de que muchos de los poemas de este libro se constituyan como un juego (especialmente los de tema erótico), son rasgos que hacen de esta escritura un correlato muy fino, en negativo, de experiencias infantiles, sobre las cuales recae una violencia compulsiva, desmedida, transgresora.

La experiencia adultizada de la infancia, que rápidamente ha sido desalojada de toda posibilidad discursiva "positiva", termina en este primer poemario de Millán marcando una pauta y unas claves de lectura para su obra posterior, acentuando su "negatividad"7. Es así como el mustio panorama que se pinta del mundo infantil termina por cerrarse en un poema como "La mutilación de los patios". Este poema y el que le sigue, "Escena original", son textos que funcionan como punto final dentro de la disposición textual interna del poemario, al hacer un entroncamiento con los siguientes poemas que hablan de la adolescencia, y bien pueden leerse como uno solo: el poema de un patio vaciado de juguetes, vaciado de experiencia infantil, donde sólo quedan los restos de un columpio, los restos de una gallina y "un puñado ruin de aserrín sucio" (p. 26), seguido de este otro poema de un niño que tiene un estrujado claxon de goma en su mano después de haber llovido y tronado, y "que interroga el misterio" (p. 27) como aventurando que hay un otro afuera de la propia experiencia; un otro descentralizado que hace crecer, que permite salir del yo infantil que se explica todo a través de sí; un otro que ha expropiado, tempranamente, la experiencia infantil.

Se trata, en consecuencia, de una infancia mutilada, la de un insecto sin alas, la de una babosa cuya experiencia se entierra bajo tierra, se descompone y fosiliza para construir desde ahí "el petrificado cuerpo-caracol del hablante de Relación personal" (Campos 1987: 43). Resulta interesante, en este sentido, observar cómo opera la figura del niño representado. Un niño-lagartija a quien se le renueva la cola en su adolescencia y adultez, pero que tiene en su inicio la experiencia de la mutilación, la marca o huella iniciática de caer al polvo sin alas, sin cola, de ahí su imagen de un ser que se arrastra por la tierra. Un ser que al faltarle una parte de su cuerpo experimenta el mundo en base a esa falta, de ahí, también, esa predilección por el encierro, por adentrarse en la tierra, por una parte, y de mutilar insectos (cuerpos), por otra.

Constatamos que el negativo de la imagen es otra de las características recurrentes de esta poesía. 
Por extensión, se trata de un ser sobre el cual recae una cierta vejez de la experiencia, una ancianidad que, como veremos, ronda en gran parte de la producción poética del autor. Se trata de una vejez complejizada por el deseo de mutilar, pero también, de manchar, deseo animal que se expresa en los otros poemas de este poemario y que se asocia, principalmente, a escenas donde aparece un otro mujer. La experiencia del amor en la adolescencia, por tanto, está cruzada igualmente por esa violencia y esa corporeidad animal incrustada en el instinto sexual infantil de su "rinconcito de experiencia confusa" (Foucault 2011: 285), que experimenta con el cuerpo femenino del mismo modo que con los insectos y su propio cuerpo.

\section{LA VIDA ANIMAL DE LOS NIÑOS}

Si bien Vida (1984) $)^{8}$ es posterior a La ciudad ([1979] 1997), creemos que plantea una continuidad respecto a Relación personal. De hecho, no por nada el autor incluye su primer poemario dentro de este otro. Son varios los temas que se cruzan y ahondan en este texto que merecen nuestra atención, de ahí el espacio privilegiado que le dedicamos. En particular, nos interesa extremar la concepción biologicista del ser humano, análoga a la de cualquier otro ser vivo. En este sentido, aquí la infancia aparece ahora en el marco de un sujeto adulto que representa al burgués de la vida moderna que se ha casado, ha formado una familia y ha tenido hijos, tal como la convención de la naturaleza social así lo exige. La experiencia del matrimonio y de la paternidad, sin embargo, se expresa de un modo problemático; al comienzo irónicamente armónico, y luego tensionado al tal punto que termina dejando huellas profundas en la descendencia a partir de la ruptura. Todo esto se produce en el marco caricaturesco de una sociedad que ha cifrado en la familia, el consumo y la tecnología toda esperanza de felicidad y porvenir.

El conjunto de poemas de la sección Vida tiene como subtítulo "Antología 19691982". A continuación, se desprenden tres secciones: Vida (un solo poema), Vida doméstica (con las subsecciones Álbum, Nido, Incubadora, Apocalipsis doméstico y O'Connors St. Blues, cada una compuesta de una serie importante de poemas) y Nombres de la era (con las subsecciones Vacaciones, Refrigerador, Automóvil, Noche y Poemas hipotéticos, también cada una con una serie importante de poemas). Explicitamos esta disposición para señalar cómo el poeta ha organizado su texto, ya que se desprende de allí una intensificación semántica que parte de una descripción sobre la vida de los seres animales (y dentro de ellos, los humanos) desde un punto de vista biológico, para luego ir generando una progresiva degradación en los sujetos a medida que se inserta en lo social, se vive en comunidad, se arma una familia (que luego se destruye), y se participa de la vida moderna, simbolizada en objetos tecnologizados como el refrigerador y el automóvil, o en el tiempo para el ocio que la sociedad capitalista destina para generar la ilusión de descanso en su programa de enajenación por el trabajo. En este contexto, la vida del niño y la niña parece estar signada por una negativa degradación, por una mancha que ensombrece toda posible

Publicado en Canadá durante el exilio del escritor, reaparece en la ya nombrada antología Trece lunas, no en su totalidad y con otra disposición de los poemas. Hemos decidido trabajar con el poemario original. La versión inserta en la antología de 1997 se inicia con el poema "Apocalipsis doméstico", decisión adoptada por el propio Millán (Piña 2007: 242). 
bella conexión con lo natural, haciendo de los sujetos sociales unos entes vivos que indefectiblemente terminarán por incrustarse en una cadena evolutiva que los llevará, en el momento histórico que les ha tocado vivir, a la alienación de la vida cotidiana.

Como señalamos, el poema "Vida" antecede a todo el conjunto. En él, mediante un habla expositiva, el sujeto plantea constantes analogías entre los diferentes seres vivos. Son particularmente interesantes las que aluden al ser humano, en especial lo referido a la concepción, primero: "El perro se monta sobre la perra. / El hombre se tiende sobre la mujer / y entra por sus piernas entreabiertas. / Los árboles se fecundan con el viento" (Millán 1984: 51), y al nacimiento, la vida y la muerte, después:

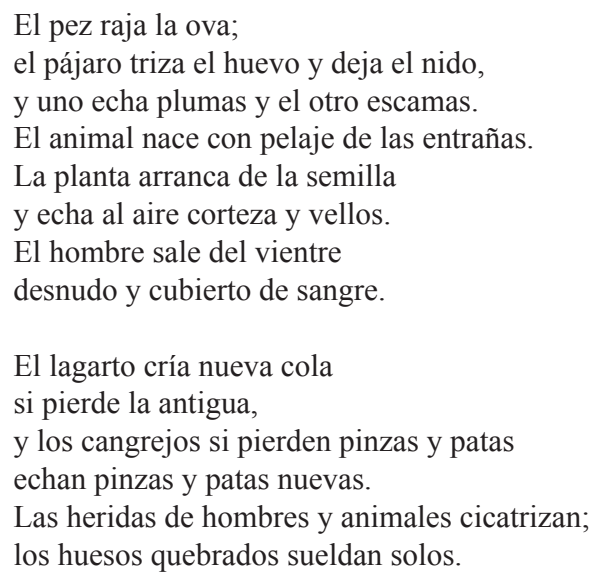

Se desgastan las células,

los órganos, los tejidos.

Disminuyen las fuerzas vitales.

La muerte es el fin de la vida (p. 52).

Como podemos apreciar, dentro del plan de vida de los seres, cualquier hecho o prescripción individual o social no afecta al conjunto de sus características y misiones esenciales: procrear, crecer, regenerarse, morir. Porque, además, como el lagarto o el cangrejo, el ser humano tiene la capacidad de cicatrizar sus heridas. El sujeto de los poemas que conforman esta obra actúa en relación con esas características: el sujeto se casa, se desvanece el amor, procrea, tiene hijos, se habla de una relación extramatrimonial y, como el lagarto, tiene la capacidad de regenerarse si pierde su cola (el rompimiento del cuerpo matrimonio). Sin embargo, a la larga, este derrotero de vida termina planteando dudas respecto a las consecuencias de este acto en sus hijos, y deja también una ventana abierta para dar cuenta de cómo el ambiente (la sociedad consumista y tecnologizada de los setenta y ochenta) constriñe a los sujetos, evolucionando, por decirlo así, de una determinación exclusivamente biologicista, a una donde el medio social también signa la trayectoria de los sujetos. Intentaremos dar cuenta de este itinerario poético que desenmascara las grandes verdades consensuadas de la sociedad contemporánea, a partir de la estrategia irónica que da cuenta del reverso, del negativo.

La sección Incubadora reúne un conjunto de poemas relativos al nacimiento de los hijos como natural consecuencia de la vida en pareja, de la cual se ha anunciado 
ya cierto vacío y desapasionamiento en las secciones anteriores, como es el caso de Álbum y, especialmente, en Nido. En este escenario, llegan nuevas vidas -de manera prematura-, lo que genera cambios y readaptaciones en la pareja, expresándose a través de la imagen de un "jinete presuroso", cuyas cabalgaduras "arrojan lloriqueantes / infantes a la tierra del regazo" (p. 81). La llegada de un niño viene, de alguna forma, a remecer todo, provocando nuevas crisis y miradas sobre la existencia. Se señala en el poema "Rama":

La casa de todos los días

es otra casa a esta hora.

La sombra de la benigna

rama se transfigura

y abalanzándose por la ventana

como la zarpa de una pantera

se extiende hacia una cuna (p. 84).

La mirada del sujeto está puesta en la amenaza de la muerte sobre la vida en el recién nacido. La casa y el árbol se transfiguran en una pantera depredadora. Algo similar ocurre en "Manzanas de mazapán", donde la muerte y su realización en el tiempo son también una preocupación en el hablante adulto maravillado por la hermosura de la hija recién nacida, cuyas rosadas mejillas son "manzanas de mazapán / donde no da aún / el tiempo tarascada" (p. 91). Las tarascadas, como sabemos, se dicen especialmente de un perro, cuando muerde o hiere con los dientes. Por último, en "Juez", el hablante equipara al recién nacido ya gateante a un insecto de ocho, seis o cuatro patas, fácil de pisotear, por lo que su suerte depende del "vacilante juez todopoderoso" (p. 91) que son los padres, los encargados de cuidar a los niños. Los símiles son evidentes y violentos: por un lado, tanto la pantera como el perro rabioso son figuras mordedoras, signos de herida y muerte; por otro lado, a la inversa, el niño es como el insecto frágil capaz de ver terminada su existencia con un simple movimiento de las manos o de los pies por parte de un ser humano. En uno y otro caso, se hace hincapié en la fragilidad de la vida puesta en entredicho por los propios seres vivos: animales o humanos, ambos son, igualmente, una potencial amenaza para el recién nacido.

Esta negatividad, sin embargo, se va disolviendo poco a poco a medida que el niño va creciendo, adquiere el lenguaje y obtiene gradualmente autonomía y madurez. Esto se grafica de manera hermosa en dos poemas. En "Oso transicional", el sujeto adulto le pregunta a su hijo qué tiene entre sus manos: el niño guarda silencio y cuando entreabre su mano, el padre descubre "el tesoro / que ha costado / al oso de felpa / un ojo de la cara” (p. 93). Sabemos, de acuerdo a la teoría psicoanalítica de Donald Winnicott sobre el "objeto transicional", que éste se configura en cuanto tal a partir del deseo del niño, quien realiza una transición simbólica de la separación con su madre en la etapa del destete. El objeto, generalmente un oso de peluche o una manta", se constituye como "la primera posesión no-yo (...) y la primera experiencia

\footnotetext{
A propósito del gusto de Millán por las historietas y como una marca de la presencia de la sociedad de masas en su poesía, una famosa tira cómica de esta época (aparece por primera vez en octubre de 1950 simultáneamente en varios periódicos norteamericanos, extendiéndose en las décadas siguientes a todo el mundo) es Peanuts, de Charles Schulz, más conocida en Latinoamérica por sus personajes estelares Charlie Brown y Snoopy. Linus, otro de los personajes del grupo, solía tener a mano una mantita, objeto transicional sin el cual no se sentía seguro.
} 
de juego" (2012: 159) del niño. En este poema, el hablante da cuenta de la incipiente separación de la unión madre-hijo a través de la acción destructiva de su hijo/a, poetizando la etapa en que el ser vivo -crío o bebé- deja poco a poco de ser un cuerpo que necesita de las asistencias y cuidados iniciales. Este hecho se evoca como remate en "Historieta de la garza y los mellizos", utilizando el cliché de los hijos como garzas que migran de un lugar a otro, abandonando el nido. Aquí, el padre comienza a vivir un duelo anticipado del fin del vínculo inicial, al estar consciente de que algún día los niños se harán grandes y dejarán el hogar:
Aletea la garza
de patas escarlatas
en manos del niño.
Como la tijera podadora
en poder de su hermano
abre y cierra el pico.
Volando sin posarse,
se alejará del dolor
hasta cansar sus alas (p. 95).

En estos dos poemas, por un lado, es posible dar cuenta del carácter destructivo de los niños, algo que ya habíamos hecho notar en Relación personal, como si los infantes de los poemas de Millán no pudieran sustraerse de esta condición. No obstante, por otro lado, la destrucción es también una posibilidad creadora, es decir, a partir de ella, a partir del juego de la devastación y la mutilación de los objetos, también surge la potencialidad de la creación. Y tal como expresa Winnicott, "en el juego, y solo en él, pueden el niño o el adulto crear y usar toda la personalidad, y el individuo descubre su persona solo cuando se muestra creador" (2012: 100). La persona que se muestra en estos juegos es la de un niño-bicho, un anormal en términos foucaultianos, experimentador, transgresor y tremendamente creativo ${ }^{10}$. Por eso, no resulta alejado señalar que otro elemento que resalta dentro del conjunto de poemas que conforman Incubadora es cómo el sujeto hablante juega de manera analógica con la figura de un niño-creador de poemas, realizando una suerte de desplazamiento de la potencia creadora destructiva hacia una de tipo constructiva. En efecto, el hablante en varias ocasiones establece esta relación, como en "Hoy no haré trabajo voluntario", en el contexto de una ciudad revolucionada por protestas callejeras:
Nada podrá detenerme,
ni barricadas llameantes
ni gases lacrimógenos.
Avanzo como un ciempiés
bajo una cáscara de huevo
llevando a casa de mi padre

10 En la terminología de Foucault (2011: 68) el anormal es un monstruo: una mezcla; mixtura de dos especies, de dos sexos, de vida y muerte, de formas. El monstruo es, de por sí, transgresión: de los límites naturales, de las clasificaciones, del marco y de la ley como marco. Creemos que lo que hace, todo el tiempo, el niño-bicho de Millán es, justamente, transgredir la norma, del mismo modo que la estética de Millán intenta trasgredir los códigos convencionales de la poesía; desdoblamiento distante del yo creador devenido en niño experimentador. 
una pequeña tina de baño

para mi hermano recién nacido.

Y no puedo detenerme.

Después escribo (p. 82).

En este poema podemos apreciar, además, al menos tres aspectos que nos parecen relevantes de precisar. En primer lugar, que en el contexto de un recién nacido el mundo y su devenir histórico se suspenden, superponiendo las urgencias y necesidades de la vida natural por sobre las de la vida social; en segundo lugar, que el sujeto concibe la escritura como un voluntariado, como un trabajo no formal del cual no se espera retribución como valor de cambio, y; en tercer lugar, que la autoconcepción animalesca del sujeto que se arrastra como el ciempiés es inseparable de toda posibilidad creadora.

La relación entre creación poética y niñez se expresa en otros poemas más. Éste es el caso de "Manzanas amarillas II", donde el sujeto formula un proceso reversivo de creación: cómo la situación antes de nacer es equiparable a un poema no escrito, no nacido:

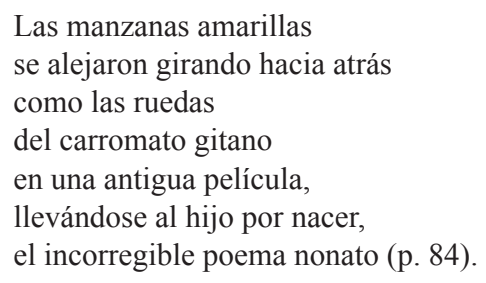

Lo mismo ocurre en "Huevo de cigüeña", cuando el sujeto describe cómo se dibuja el rostro del hijo en un jabón oval. Después de caracterizar su cara, sus extremidades y sus ojos, termina el poema señalando: "Sus rasgos de espuma enguantan / mis manos sucias que dan a luz" (p. 86). Manos sucias, manos entintadas por el lápiz, manos que escriben el poema ${ }^{11}$; todas estas analogías dan cuenta de la intencionalidad creativa del autor por establecer relaciones personales que impersonalizan, que universalizan la experiencia, característica que, según vimos, se hacía presente desde los inicios de su producción poética.

Dentro del poemario, la sección Apocalipsis doméstico da cuenta del fin de la relación matrimonial a través de una progresiva degradación. Dicha sección acaba con el poema del mismo nombre, en donde se describe de manera detallada la situación del hogar en decadencia, descuidado y sucio, donde todos los objetos signos de la boda aparecen derruidos, desgastados o rotos. Es llamativo el uso de palabras como: gastar, agujeros, quebrar, perder, tarjar, acabar, vacío, restos, cortar, apagar, terminar, desvanecer, trizaduras, migajas, asfixiar, etc., todos términos que isotópicamente realizan la idea de un final apocalíptico, de un término abrupto y terrible de la vida doméstica. Existe, además, una disposición temporal mediante la utilización de verbos en pasado, presente y futuro que hace de ésta una sola acción condensada en el tiempo, permanente, duradera, intensa. En este contexto de desolación, casi

\footnotetext{
También es posible hablar del poema "Manzanas amarillas III" como parte de este núcleo temático, donde habla del hijo como un poema y del lector como un padre.
} 
como un campo devastado de guerra, aparecen algunas alusiones a la infancia que queremos rescatar aquí y que guardan relación con este escenario de abandono. Dice el hablante: "En el refrigerador hay solamente / una mitad de cebolla estriñida / y una mamadera con leche agria" (p. 116). Luego agrega: "No queda ropa limpia. / Hay pañales sucios en la tina. / Se le cayó el último botón / que le quedaba a la camisa" (p. 117). Y finaliza:

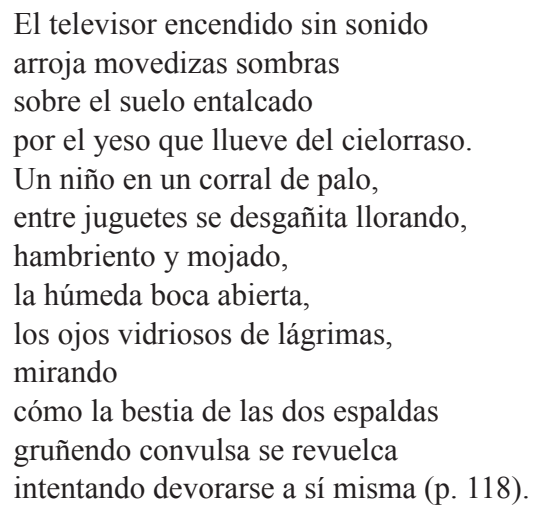

La situación de devastación doméstica recae sobre el niño en su corral de manera trágica. Está sucio, hambriento y lloroso, abandonado del mismo modo que la casa y el amor, mirando a esta bestia de dos espaldas que se revuelca intentando devorarse a sí misma. La imagen es fuerte y la interpretamos como la representación del acto sexual, que aquí se da de manera animalesca, en la pura liberación autodestructiva del instinto del acto amoroso realizado sin amor, tal vez, en la búsqueda reparatoria y desesperada de lo roto. Llama la atención, sin embargo, que el niño es el espectador aterrado de la escena, operando sobre él la visión involuntaria de algo inapropiado.

Esta situación inadecuada puede actuar como trauma, y nos recuerda a Hans, uno de los primeros casos estudiados por Freud en "Análisis de la fobia de un niño de cinco años (el pequeño Hans)", en donde sugiere, sin llegar a comprobarlo, que una posible causa de las fobias sexuales neuróticas desarrolladas por algunos niños pequeños puede tener su origen en el hecho de haber presenciado en el dormitorio de sus padres lo que él denomina la escena primordial o "el comercio sexual entre los padres" (Freud 1978a: 109). Esta teoría, desarrollada en extenso en "De la historia de una neurosis infantil (el Hombre de los Lobos)", vincula de manera compleja esta observación involuntaria del coito entre los padres -ya sea fantasía o suceso real- con los impulsos de mutilación de insectos, por una parte, y con el miedo a la castración, por otra parte, evidenciado en el análisis del Hombre de los Lobos con la conjugación de otros factores de su personalidad. Si nos valemos del relato de la teoría psicoanalítica, no parece lejano señalar que el niño de la cuna del poema "Apocalipsis doméstico" puede funcionar como antecedente infantil del niño-bicho de los poemas de Relación personal: anormal, monstruo, cruel y experimentador, que luego en la adolescencia manifiesta un afán por "degradar el objeto de amor" (Freud 1978b: 86), del mismo modo que degrada el objeto de sus juegos.

La quinta y última sección de Vida doméstica, titulada O'Connor St. Blues, cierra el conjunto aludiendo a la idea de una huerfanía. Abre la sección un epígrafe en inglés 
tomado de una canción spiritual, esto es, del canto cristiano de origen afroamericano, que dice: "Sometimes I feel like a motherless child a long, long way from home". El sujeto se representa a sí mismo en una condición de orfandad, como un niño que se halla lejos de casa, específicamente lejos de su madre, y que comienza a tener conductas degradantes, por ejemplo, como un bebé que se emborracha con cerveza: "Bebes a tragantadas mamaderas / con una leche amarilla y agria / y sabor a lúpulo de tu mamamala" (p. 131). En esta nueva vida en soledad, bajo este panorama, el sujeto repasa lo que ha sido su vida, las circunstancias del fin del amor, intenta resurgir con proyectos y echa de menos a sus hijos. Ahora, la reflexión sobre la infancia adquiere otro cariz: es el sujeto quien se ve como el niño del corral de "Apocalipsis doméstico", abandonado, triste, lloroso y hambriento de humanidad, de amor, con una mamadera que ahora es mamamala.

Esta situación de incompletitud en medio del ambiente social es lo que termina por refrendarse en la última parte de Vida (1984) titulada Los nombres de la era, sección en donde el sujeto intenta denominar el momento de vida actual, de creciente tecnologización, que ha modificado las conductas de los individuos. La sección comienza con un epígrafe de W. H. Auden, que dice: "And had everything necessary to the Modern Man, / A phonograph, a radio, a car and a frigidaire". Con esta ironía inicia una lectura que cuestiona la constitución identitaria de las personas por medio de objetos representativos de la vida moderna. Qué pasa con la infancia es, precisamente, una pregunta que se realiza el sujeto en virtud de la interacción con estos objetos, por ejemplo, con el refrigerador, como se desprende del poema "Niño":

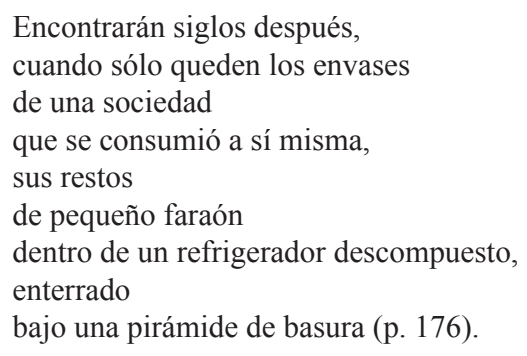

Bajo la analogía con la tradición de la antigua cultura egipcia de enterrar a los muertos de la clase alta, los faraones, en amplias bóvedas selladas junto a todas sus riquezas, el hablante realiza aquí una proyección al futuro, dando cuenta del destino de la sociedad de consumo que fabrica día a día toneladas de basura, especialmente envases plásticos. Este cúmulo de desechos será como una pirámide egipcia, y allí estará el niño de la sociedad moderna enterrado en su sarcófago -símbolo de la era en que se vive-: un refrigerador. La ecocrítica se intensifica al elegir a un niño como sujeto de la acción, puesto que en él recae el futuro de la sociedad. El mensaje es más bien pesimista, al indicar lo incuestionable del avance de una cultura que se dirige hacia su propia destrucción.

Algo similar ocurre respecto del automóvil, el cual es utilizado por el sujeto para hablar de la dislocación de los gustos de los niños a partir de la fascinación que sienten por la tecnología y los viajes interplanetarios, como en el poema "Viajeros del futuro", en donde se habla de niños que conocen todas las marcas de los automóviles que corren por la carretera, pero que no saben los nombres de las estrellas "adonde 
sueñan con viajar / en naves espaciales / más veloces que la luz” (p. 193). Estos niños cautivados por el automóvil y los viajes interplanetarios tienen sueños de modernidad, pero desconocen el mundo natural del cual forman parte. En ese desplazamiento de los saberes e intereses de los niños, se da cuenta de un parecer poco auspicioso respecto del devenir de la sociedad de masas.

\section{LA NIÑA-ANCIANA}

El poema $L a$ ciudad $^{12}$, quizás el más conocido del autor, ha sido estudiado principalmente desde su veta político-histórica como una suerte de crónica crítica del periodo de dictadura militar en Chile (1973-1990). Sin embargo, creemos que poco se ha ahondado acerca de quién habla en él. El sujeto hablante que escribe el poema se autodenomina como una anciana, estableciendo un cambio radical respecto de su primera versión ${ }^{13}$. Es un sujeto que habla desde la ancianidad temporal y desde la ancianidad constructiva del poema, y que regularmente recurre a la infancia del poema para enunciar desde ahí cómo nace y se construye el texto. Por eso, para nosotros viene a ser más bien una niña-anciana, una anciana que se hace niña creadora de un poema llamado "La ciudad". En su edad, esta hablante es portadora de un saber que rescata, a través de la memoria, el sentido histórico de esta ciudad sitiada. La figura original del profesor de historia que lo encarnaba se conserva ahora devenida en mujer, quien, a su vez, remite en pasajes importantes del poema a la experiencia de dar a luz, de la procreación como acto de vida.

La revelación del sujeto hablante no se da sino al final del largo poema de 73 fragmentos ${ }^{14}$. Dice en los dos últimos versos del poema 50: "La anciana compone un poema. / El poema habla de una ciudad” (Millán [1979] 1997: 253), e inmediatamente después, comenzando el poema 51: "La anciana es viuda. / La anciana no tuvo hijos. / Un sobrino es el báculo de su vejez. / El poema de la ciudad es su hijo" (p. 253). La anciana escribe un poema sobre la ciudad y ese poema es su hijo. La anciana da a luz un hijo. Vemos cómo Millán juega con la metarreferencialidad del texto, cómo construye y revela su artificio, poniendo en manos de esta anciana el acto de crear un poema que es viejo, que mira para atrás, que es reversivo, pero que al estar escrito usando la forma verbal del presente, se realiza en el momento de la lectura. Esto permite que como lectores podamos asistir al acto de creación del poema: a su concepción, nacimiento, vida y muerte.

Por eso, en el poema 64, la anciana cuenta su infancia, ya que: "Se aproxima mi fin. / Se aproxima el fin del poema" (p. 266). Muerte (fin del poema) y nacimiento

\footnotetext{
Trabajamos con la edición de 1997 incluida en Trece lunas, y que guarda muchos cambios respecto a ediciones anteriores, especialmente en relación con la original de 1979. La última edición que se conoce es de 2007, con levísimos cambios más de forma que de contenido.

13 En la primera edición de 1979 el hablante es un anciano. El cambio no nos parece menor. Como apunta Ayala (2010: 76), existe en este procedimiento una suerte de suavización de la figura hablante. Mientras el anciano es representativo de un momento político-histórico de dictadura (escrito en el exilio), la anciana es representativa de la transición a la democracia (reescrito en Chile). Se trata de una figura menos política y antagónica, y simbolizante del carácter mítico y regenerativo de la vida.

14 Conjeturamos, al mismo tiempo, que el hecho de que el autor haya escogido 73 fragmentos para su poema no es casualidad. No sólo alude al año del golpe militar en Chile, sino que también puede ser atribuible a una edad anciana, a una escritura que represente la edad desde la que se escribe.
} 
(creación del poema) se unen aquí en esta figura de la anciana que ahora da cuenta de su evolución en un paralelo que se corresponde con el fin de año y el festejo por uno nuevo: al mismo tiempo que se saca la última hoja del calendario y se elevan y estallan los cohetes iluminando la noche de festejo, la anciana "sale del claustro materno" (p. 266), "ve la luz" (p. 267) y el sol ilumina la tierra. Luego, viene la progresión del ser humano: la anciana está en pañales, bebe leche de las mamas, le fajan el ombligo, le cae baba de la boca, usa babero, mueve el sonajero de la cuna, se orina, gatea, balbucea, se tambalea, camina y "rompe a hablar" (p. 267). Luego nombra, imita, se asombra, se calla, dibuja, remeda y juega, para finalizar con los dos últimos versos: "La anciana se pasa el tiempo jugando. / Inventa una ciudad de juguete" (p. 268): la ciudad del poema.

Como creación dentro de una creación, apreciamos la puesta en abismo como parte constitutiva de la construcción del poema, como si la niña anciana y su ciudad estuvieran dentro de una bola sostenida por la mano de la hablante que, al mismo tiempo, erige su poema de la ciudad; o, como si esa imagen se reflejara en un espejo, proyectando la imagen y la imagen de la imagen. Dice la hablante comenzando el poema 65: "La anciana se mira al espejo. / El espejo remite las imágenes. / El poema es un espejo" (p. 268). Finalmente, cuando la anciana termina su vida y da a luz sus versos postrimeros, cierra con ello también el poema. Esta tradición de corte medieval de la unión de los extremos de la vida, por un lado, y la estructura especular de sus textos, por el otro, creemos que son otras dos características esenciales de esta poesía, y que se irán a reunir magistral y profundamente en relación con la infancia en Autorretrato de memoria (2005). Ambas funciones no sólo dan cuenta de una compleja concepción de la poesía, sino que, en lo que se refiere a la visión de la infancia, ésta forma parte de manera ineludible de este proyecto escritural que excava hacia atrás del ser y hacia atrás del poema.

\section{LA IMAGEN INCOMPLETA DEL ESPEJO}

Autorretrato de memoria es un poemario publicado en 2005, en los últimos años de vida de Millán, y guarda una íntima conexión con su poética anterior, especialmente con su primer libro. Compuesto de veinte poemas, cada uno de los cuales puede ser entendido como un cuadro que intenta dar una representación ficcionalizada del yo, este poemario mezcla muy bien artes visuales y poesía, de modo similar a como lo había hecho con anterioridad en Claroscuro (2002), y en su póstumo Gabinete de papel (2008). Al igual que en estos poemarios, aquí es posible encontrar frecuentemente juegos y guiños a los códigos de la representación pictórica, como el contraste que se genera en el trabajo de luces y sombras, y de la representación fotográfica, a partir del interés por el negativo, la miniatura decolorada que revela el envés o espalda de la imagen. Estas concepciones estéticas entran en dinamismo en este texto, en conjunción con temas como la memoria y la infancia, temas que nos interesa profundizar a continuación.

Abre el libro un epígrafe sin atribución a ningún autor, que dice: "Todo pintor se pinta a sí mismo", introduciéndonos como lectores inmediatamente a la idea de una especularidad del poeta-pintor que escribe-pinta con "los lentes ahumados (...)/ las limosnas de la memoria" (Millán 2005: 15), es decir, con una vista parcial, nublada, 
con los recuerdos de una vida que ya está avanzando rápidamente hacia la muerte, dependiente, a su vez, de una memoria incapaz de recordarlo todo. En este sentido, este poemario, en conjunto con su diario de muerte Veneno de escorpión azul (2007), funcionan como textos que en lo tocante al tema de la infancia unen los extremos de la vida: el germen y su fin, el niño y el anciano, desde un sujeto viejo consciente de la proximidad de la muerte, que busca en ella una trascendencia: "un volver a nacer" (Tesche y Sancho 2012: 109). Es en esta instancia de memento mori cuando el hablante hace un recuento de su vida, desde sus orígenes, buscando un nuevo sentido en el repaso y en el momento de la incertidumbre ante lo que hay después de la vida. Así, se pone en juego la doble función que tiene la revisión del pasado en su calidad de disolución, pero también de promesa:

Disolución porque su manifestación es residual dado que existe como resto de lo perdido, y promesa porque está disponible para ser leído desde el presente y mediante nuevas coordenadas de interpretación que revelan formas inéditas de entenderlo (Saraceni 2008: 15).

No por nada otro de los paratextos que anteceden al conjunto de poemas, tomado del filósofo taoísta chino del siglo V a.c, Chuang-Tzu, dice: “¿Cómo puedo yo saber / que amar la vida no es una trampa? / ¿Que odiar la muerte no es extraviarse / como se pierde un niño al regresar a casa?". Como ese niño del poema, el hablante regresa a casa y en el trayecto se pierde. Con "una lucidez dudosa" (p. 15) y con anteojos ahumados, regresa, pero con dificultad. El resultado es este poemario intensamente dedicado a la infancia desde la muerte, al niño desde el viejo moribundo, sospechoso de la proximidad de su fin, pero para quien recordar es un despertar que da lucidez creativa y capacidad de articulación de un dispositivo poético que juega con las huellas del yo en un lienzo en blanco, sentado en su gabinete, pintándose a sí mismo bajo nuevas coordenadas de interpretación.

Los ojos del niño aparecen en un poema como "Autorretrato con escenas poco originales", en donde se pinta a un niño encerrado dentro de un armario, primero, y dentro de una pieza, después. Desde el alcanfor, a partir de una pequeña grieta que es como una cámara fija que sólo da una forma parcial de mirar, el niño ve a sus "primeros padres / como cortados fragmentos de una tira cómica / cómica" (p. 17). Desde la pieza, en tanto, el niño ve detrás del montante, en la pequeña ventana de la puerta, "las sombras más fascinantes y terribles" (p. 17), las que parecen ramas que se mecen con el viento y que representan, a su vez, a un águila negra con una gallina y a un gallo luchando con una serpiente. El hablante se autorrepresenta aquí en un cronotopo que muestra a un niño fascinado en su escondite, por un lado, y asustado con el movimiento del viento detrás de la ventana, por otro. Como expresa el título, se trataría de "escenas poco originales" de la infancia. Aluden a experiencias universales de fascinación y terror que han sido largamente utilizadas por la tradición pictórica y narrativa, dos escenas prototípicas que terminan siendo vaciadas en su poca originalidad, mostrando una copia que resulta más bella que la original. Ambas escenas, sin embargo, refuerzan el punto de vista del hablante como la de un sujeto que mira, observa y trata de dar cuenta de aquello que ha visto. Llama la atención, eso sí, que en la primera "vista" lo visto hayan sido sus "primeros padres", como si después hubiese habido otros. Ésos, tal vez, responden a los que lo formaron en su manera de ver. 
Un conjunto de poemas que hablan específicamente de la relación entre madre e hijo es el compuesto por "Recado bajo un magneto en un refrigerador Crosley", "Yacente" y "Autorretrato lúgubre". En el primero, se muestra a un niño que deja un inquietante mensaje en el refrigerador:

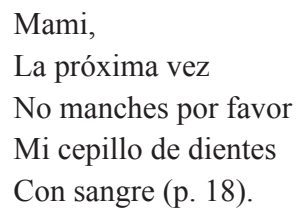

En estos versos apreciamos la idea de una infancia tensionada por una vida adulta, encarnada en la figura de una madre que mancha al niño, que lo signa y deja una huella en él. El recado es reclamatorio, es una queja realizada indirectamente, no cara a cara, dejada allí para que todos se enteren. Como acto de lenguaje, pareciera ser una petición de un niño hacia su madre para que no se interponga, respete su espacio propio, su privacidad. Ahora bien, quizá no se trate sólo de un simple mensaje: la sangre indica también filiación, herencia de la cual el niño no puede huir. Su vida entera ha quedado lacrada por esa mancha. Mancha, por lo demás, proporcionada por la madre, no por el padre. Resulta aclaratorio enterarse, en este sentido, de cuál es la visión que el sujeto tiene de su madre.

La respuesta viene junto al poema "Yacente", el cual se acompaña de un epígrafe aún más aclaratorio tomado de Gustave Flaubert: "Abramos nuestros propios recuerdos / ¡Cuántas tumbas!”. El poema es un retrato de la madre, pintada de esta manera: "Aquí yace la autora de mis noches / Con la mano en la mejilla y en la cara / Pegada la tristeza del domingo por la tarde" (p. 26). Esta madre, autora de sus noches y no de sus días como expresa la frase popular, es representada moribunda, casi muerta, "con sábanas de mármol" (p. 26), melancólica, adicta a los fármacos y a la nicotina, "un sarcófago de humo" (p. 26), sentada como una estrella de cine con su silla ante el espejo, pero con un permanente siseo de serpiente a su alrededor. Sabemos que en la tradición cristiana la serpiente representa el pecado, el mal, la muerte. El cuadro que pinta-escribe aquí el poeta-pintor es un cuadro oscuro, terrible, de una madre que mancha, que ha manchado al sujeto.

Atendiendo aspectos de la biografía del autor, parece pertinente comentar aquí el suicidio de la madre del poeta cuando éste tenía 21 años. Al tratarse estos poemas de autorretratos autobiográficos como metáforas del yo impersonal millaniano, "enmascarado o encubierto detrás de los objetos que lo desplazan a un lugar sin nombre" (Hernández 2008: 128), no parece descabellado establecer esta relación y concluir que el recuerdo de la madre ha quedado signado para siempre en la mente del sujeto bajo este triste fin. Se entiende de mejor modo, entonces, retrocediendo hacia atrás, la queja del niño con su cepillo ensuciado por la madre.

Este recuerdo oscuro se completa con el poema "Autorretrato lúgubre", antecedido nuevamente de dos esclarecedores epígrafes. Uno del poeta Amado Nervo que dice: “¿Mi secreto?” Te lo diré al oído: / ¡Estoy enamorado de una muerta!”. Y el otro es una expresión mapuche que dice: "Yo mismo me morí cuando se murió mi madre". Ambos textos y el título se comunican con el poema indicando el tono adecuado para su lectura. Resulta sugerente destacar aquí que el sujeto tiene una linterna 
en su poder, y con ella alumbra toda posible oscuridad, alumbra la muerte de su madre, enamorado de ella. El sujeto se denomina a sí mismo como el "guardián de una memoria envenenada. / El sereno de un museo de cera" (p. 28), expresando de manera tácita el dolor, por un lado, y dando cuenta de cómo está configurada su memoria, llena de agrios recuerdos, por el otro. Recuerdos que parecen conformar un detenido museo repleto de falsas figuras de cera, el que, a su vez, ha oscurecido su adolescencia y, por extensión regresiva, su infancia en tanto negativo del momento actual de escritura, en tanto imagen silueteada que se desvanece con los años.

Es por todo lo anterior que no llama la atención que el sujeto se autorrepresente desvalido, solitario y pálido en "Autorretrato como pichón de paloma". En este poema, el hablante dice de sí: "Estoy de pie como un pichón / en el nido cagado. / Me destaco sobre un fondo de tinieblas / por mi plumosa palidez de grisalla" (p. 35), es decir, como un sujeto con diferentes tonos de gris, como cría de paloma, pequeño y en un nido excretado. En una casa manchada, con un fondo de tinieblas, alumbrado en medio de la oscuridad, se halla un niño-luz que pareciera tener una temprana visión de la muerte. Un niño que ha visto todo, antes de tiempo. Un niño pequeño como pichón, pero viejo, signado por la muerte.

De ahí a un poema como "Autorretrato con calavera" sólo hay un paso: "Estoy sentado en las rodillas huesudas / de una calavera / vestida con largas ropas de mujer" (p. 37), para luego rematar:

La calavera sonríe sin boca y sin labios.

Sonríe orgullosa mirando el esqueleto

Del niño nonato acunado en su regazo.

Estoy tan leve en sus manos

Como las migas de una hostia,

Amparado cual esqueleto de una hoja

O un caracol vacío (p. 37).

En este poema, como podemos apreciar, el sujeto se autorrepresenta como un nonato mecido por las manos de una calavera. Es el mismo niño-caracol de Relación personal. Un niño, en conclusión, cuya infancia pareciera no haber nacido nunca. Una infancia trunca, manchada. Un niño nacido muerto: el negativo de la infancia. Un niño no nacido niño, sino ya viejo. Y por cuyo cuerpo y cuya memoria quedan las huellas que el poeta ha intentado revivir y pintar en su poema-lienzo en blanco.

\section{Conclusión}

Señalamos a lo largo de este trabajo que la infancia en la poesía de Millán constituye uno de sus ejes centrales, poblando su poesía de un aura desacralizadora de cualquier visión tradicional respecto de la niñez. El modo de lograrlo es haciendo jugar a un niño cercenador de insectos. Este niño, a su vez, posee características animales. Es un niño-bicho, un anormal, cuya experiencia inicial es el trauma de la escena primordial freudiana que deriva en una fascinación destructiva: la mutilación. De ahí proviene la imagen de un ser que se arrastra por los espacios y su deseo de amputar cierta violencia que signa su cuerpo y lo hace presentarse desde pequeño ya experimentado, viejo, antes de tiempo. De todo esto se desprende que la vida 
de los niños pareciera estar marcada por una negativa degradación, proceso que se vive de la mano con la alienación de la vida cotidiana moderna, encandilada con el progreso tecnológico. Toda esta potencialidad destructiva del sujeto, no obstante su anormalidad transgresora, tiene la posibilidad reversiva de volverse juego constructivo, creación.

Esto se da, efectivamente, con la creación de un poema sobre una ciudad, y de este poema y esta ciudad como un juguete en la mano escribiente de una niña-anciana que se mira al espejo para desentrañar(se) la existencia. Ahora ya desde la ancianidad, desde la proximidad de la muerte, en el juego especular de los reflejos pero con la vista nublada por la edad, infancia y vejez terminan por unirse como potencias desgarradas de una existencia vivida desde el borde como anormalidad, como un rinconcito confuso y experimentador, desde la experiencia de la vida moderna y con las marcas corpóreas de esa experiencia. Valiéndose de la ironía y del negativo de la imagen, el sujeto de gran parte de la poesía de Gonzalo Millán vuelve a casa y, en ese trayecto, en ese renacer ayudado por el ejercicio de la memoria, termina por tensionar las experiencias vitales comunes de los seres humanos de la época moderna.

\section{OBRAS CITADAS}

Arroyo, Guido. 2012. "El rostro a la luz de una mecha". En Millán, Gonzalo, La poesía no es personal. Santiago: Alquimia Ediciones. 5-14.

Ayala, Matías. 2010. "Dictadura, transición y reescritura en Gonzalo Millán”. Chasqui XXXIX.1: 64-80.

Campos, Javier. 1987. La joven poesía chilena en el periodo 1961-1973. Concepción: Lar.

Foucault, Michel. 2011. Los anormales. Buenos Aires: Fondo de Cultura Económica.

Foxley, Carmen. 1991. "La negatividad productiva y los gajes del oficio. La poesía de Gonzalo Millán”. En Foxley, Carmen y Ana María Cuneo, Seis poetas chilenos de los sesenta. Santiago: Universitaria. 54-86.

Freud, Sigmund. 1978a. "Análisis de la fobia de un niño de cinco años (el pequeño Hans)". En Freud, Sigmund, Obras completas, X. Buenos Aires: Amorrortu. 1-118. 1978b. "De la historia de una neurosis infantil (el Hombre de los Lobos)". En Freud, Sigmund, Obras completas, XVII. Buenos Aires: Amorrortu. 1-112.

Galindo, Oscar. 2004. "Distopía y apocalipsis en la poesía de Oscar Hahn y Gonzalo Millán”. Anales de Literatura Hispanoamericana 33: 65-76. . 2007. "Palabras e imágenes, objetos y acciones en la postvanguardia chilena". Estudios Filológicos 42: 109-121.

Hernández, Biviana. 2008. "Gonzalo Millán y la subjetividad fragmentada del autorretrato". Estudios Filológicos 43: 115-130.

Millán, Gonzalo. 1984. Vida. Ottawa: Ediciones Cordillera. 1997. "La ciudad". En Millán, Gonzalo, Trece lunas. Santiago: Fondo de Cultura Económica. 193-281.

2005. Autorretrato de memoria. Santiago: Ediciones Universidad Diego Portales. 2006. Relación personal. Santiago: Ediciones Universidad Diego Portales. 2007. Veneno de escorpión azul. Santiago: Ediciones Universidad Diego Portales.

Morales, Leonidas. 2009. Formalismo y ambigüedad. Poesía chilena de los sesenta. Santiago: Cuarto Propio.

Piña, Juan Andrés. 2007. "La persistencia de la memoria”. En Piña, Juan Andrés, Conversaciones con la poesía chilena. Santiago: Ediciones Universidad Diego Portales. 215-253.

Saraceni, Gina. 2008. Escribir hacia atrás. Buenos Aires: Beatriz Viterbo Editora. 


\section{ESTUDIOS FILOLÓGICOS 56: 33-50, 2015}

Tesche, Paula y Noemí Sancho. 2012. "Cuerpos agónicos: Representaciones de la muerte en tres poetas chilenos". Literatura y Lingüistica 26: 101-113.

Winnicott, Donald. 2012. Realidad y juego. Buenos Aires: Gedisa.

Zaldívar, María Teresa. 1998. "La mirada de Millán”. En El Mercurio, domingo 7 de junio, p. E16. 